\author{
Visión Electrónica \\ Más que un estado sólido \\ https://doi.org/10.14483/issn.2248-4728
}

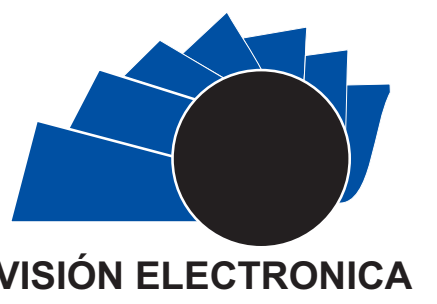

A Research Vision

VISIÓN ELECTRONICA

UNIVERSIDAD DISTRITAL

FRANCISCO JOSÉ DE CALDAS

\title{
Wavelet transform to induction motor analysis: review.
}

\author{
Transformada wavelet para análisis del motor de inducción: revisión.
}

\author{
Carmenza Moreno-Roa ${ }^{1}$,Adolfo Andrés Jaramillo-Matta² ,
} Oscar David Flórez-Cediel ${ }^{3}$

\section{INFORMACIÓN DEL ARTICULO}

Historia del articulo Enviado: 27/07/2018

Recibido: 02/10/2018

Aceptado: 16/11/2018

\section{ABSTRACT}

This study makes a revision of the most recent investigations that have implemented the wavelet transform by analyzing the electrical and mechanical variables of the induction motors. The investigations can be grouped into three main topics: diagnosis and detection of faults, control and detection systems and the classification of electromagnetic disturbances.

\section{Keywords:}

Induction motor

Transform

Wavelet

\section{Palabras clave:}

Motor de inducción,

Transformada,

Wavelet.

\section{RESUMEN:}

Este trabajo realiza una revisión de las investigaciones más recientes que han implementado la transformada wavelet analizando las variables eléctricas y mecánicas de los motores de inducción. Las investigaciones se pueden agrupar en tres temas principales: diagnóstico y detección de fallas; sistemas de control y detección y la clasificación de perturbaciones electromagnéticas.

\footnotetext{
BSc. In Mathematics, Universidad Distrital Francisco José de Caldas, Colombia. MSc. In Mathematics, Universidad Nacional de Colombia, Colombia. Current position: Professor at Universidad Distrital Francisco José de Caldas, Colombia. E-mail: cmorenor@udistrital.edu.co. ORCID: https://orcid.org/o000-0002-6947-8198.

${ }^{2}$ BSc. In Electronic Engineering, Universidad del Valle, Colombia. MSc. In Electronic Engineering, Universitat Rovira i Virgili, Spain. Ph.D. In Electronic, Automatic and Telecommunications Engineering, Universitat Rovira i Virgili, Spain. Current position: Professor at Universidad Distrital Francisco José de Caldas, Colombia. E-mail: ajaramillom@udistrital.edu.co. ORCID: https://orcid.org/0000-0002-9743-5638.

${ }^{3}$ BSc. In Electricity Engineering, MSc. In Electric Engineering, Universidad de los Andes, Colombia. Current position: Professor at Universidad Distrital Francisco José de Caldas, Colombia. E-mail: odflorez@,udistrital.edu.co. ORCID: https://orcid.org/oco0-0002-0653-0577.
} 


\section{Introduction}

The electrical actuators that contain three-phase induction motors are the more often used in the Industrial sector, it is estimate that the $70 \%$ of electrical energy that is used in industrial applications come from of induction motor [1]. The preference in respect to use it, is mainly because of the advantages that it presents in robustness, low cost, constructability, high reliability, minimum maintenance, among other ones.

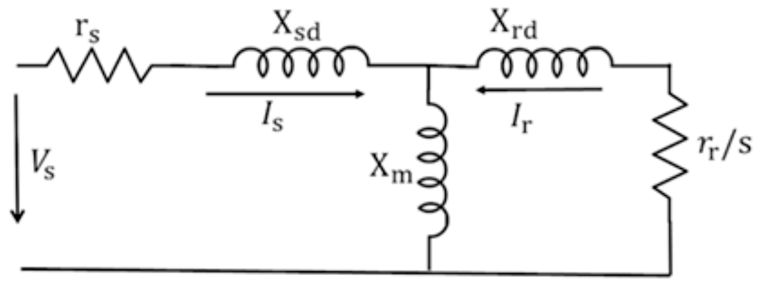

Figure 1. Equivalent electric circuit, per phase, of the model in permanent regime of the three-phase

IM, for the single cage model, [2].

A lot of researches have been devoted to explain and grasped the mathematical relations of the mechanical and electrical variables that involve the operation of three-phase motor of induction (IM). For that purpose, it had been built different mathematical models that represent the performance in its variables. One of the commonly used is the simple cage with five parameters, which electric circuit equivalent is represented in [2]In this model the electric and mechanical variables the most interest are currents and voltages present in the stator, the speed and the torque on the shaft. The model parameters are the resistance of the stator $X s d$, the reactance of the rotor $\mathrm{Xrd}$ and the magnetizing reactance $X m$.

The variables: current, voltage, torque, and shaft speeds, are magnitudes that depends on time, usually called Signals. The performance of this signals provide information about functioning of the Three-phase motor of induction. The Fourier's transform, proposed by Jean Baptiste Joseph Fourier (1768-1830) and the Fourier's Transform in Short Times (FTST) by Denis Gabor (1900-1979) had been used widely for the signal analysis. To apply this transforms to a signal with domain in the time, it results a signal in the frequency domain, which present different properties very useful for Physical and engineering analysis.

In addition, to make an analysis about the frequency of a signal without regarding the variation in the time, or when the signal is invariant in the time, it means a stationary signal, for the situation it is useful the Fourier's transform. When it is want to analyze the signal in its domain of time and frequency, or the signal changes its frequency in the time, the signal is called non-stationary. In this cases it is used the FTST to make an analysis in a section of the signal to through a fixed time interval window. In the situation presented is not possible to analyze details of the variable frequency in different lengths of time intervals, since the window has an equal length for all frequencies.

For the study of non-stationary signals there is a relatively recent mathematical concept called the Wavelet Transform (WT), presented by Jean Morlet and Alex Grossman in 1984. The WT offers the possibility of studying signals longer time intervals for low frequencies and shorter time intervals for high frequencies. This can be considered as an advantage of WT about FT. Firstly, because it allows visualizing the performance of the signals in time and frequency simultaneously, and secondly because it allows the analysis of short transients. The WT takes a signal that is in the time domain and transforms it into the time and frequency domain. Although voltage, current, torque and speed signals are domain functions in time, in many cases, the most relevant information of them is in the frequency content, this is what motivates the use of the WT in the applications to signal analysis.

In this article, the review is made by the research work in which the WT has been put into practice to analyze electrical and mechanical signals of the IM. In section 2 some basic concepts of the WT are exposed, in section 3 some of the investigations in which the WT is used for the diagnosis of faults, control systems and electromagnetic disturbances are presented. Finally, in section 4, there are the conclusions that can lead future work of WT to the analysis of the IM performance.

\section{Wavelet Transform}

To talk about the WT, it is essential to mention the TF because, on the one hand, the definition of WT is based on the TF, and on the other hand, it is found that with the two transforms it is intended to represent a function in terms of other functions called bases. Once the WT is defined, the Multi Resolution Analysis (MRA) is defined, which is the theoretical foundation of the algorithm that allows the theory of the WT to put in practice.

\subsection{Fourier's Transform}

By the Fourier Theorem we have that the periodic 
functions can be decomposed into sinusoidal functions of different amplitudes and frequencies. This is what the equation represents (1).

$f(t)=\frac{A_{0}}{2}+\sum_{n=1}^{\infty} A_{n} \operatorname{sen}\left(\omega_{n} t\right)+B_{n} \cos \left(\omega_{n} t\right) \quad \operatorname{Con} \omega_{n}=\frac{2 n \pi}{T} n \in \mathbb{N}(1)$

Terms $A_{n}$ and $B_{n}$ are called the coefficients, $W_{n}$ the frequency and the elements of the decomposition base are the functions $\operatorname{sen}\left(W_{n} t\right)$ and $\cos \left(W_{n} t\right)$.For non-periodic functions, the Fourier Transform (FT) is used, which assumes the infinite period and transforms a function $f$ with a domain in time to a function $\mathrm{F}$ with a domain in the variable frequency $w$ as shown in equation (2).

$$
F(\omega)=\frac{1}{\sqrt{2 \pi}} \int_{-\infty}^{\infty} f(t) e^{-i \omega t} d t \quad \omega \in \mathbb{R}
$$

\subsection{Some basic concepts about Wavelet transform}

It is said that a function $\psi$ is square integrable (or finite energy) if it meets the inequality (3)

$$
\int_{-\infty}^{\infty}|\psi(\mathrm{t})|^{2} \mathrm{dt}<\infty
$$

The space of all square integrable functions with the norm defined in $(4)$ is called $L^{2}(\mathbb{R})$.

$$
\|\psi\|_{L^{2}}:=\left(\int_{-\infty}^{\infty} \psi^{2}(t) d t\right)^{1 / 2}
$$

Now, a square integrable function is a Wavelet (or Mother Wavelet) if it also satisfies the admissibility condition shown in $(5$. Where $\hat{\psi}(\omega)$ is the Fourier Transform of $\psi(\omega)$.

$$
C_{\psi}:=\int_{-\infty}^{\infty} \frac{|\widehat{\psi}(\omega)|^{2}}{|\omega|} d \omega<\infty
$$

If in addition to admissibility, condition (6) is satisfied then the condition (7) will be satisfied the accordingly.

$$
\begin{aligned}
& \int_{-\infty}^{\infty} \psi(t) d t<\infty \\
& \int_{-\infty}^{\infty} \psi(t) d t=0
\end{aligned}
$$

From a Mother Wavelet we define a family of functions that are compositions of translations and expansions of it, which are modeled as in equation (8). Where $u$ indicates the translation and $s$ indicates the dilation of respectively

$$
\begin{gathered}
\psi \\
\psi_{s}^{u}(t)=\frac{1}{\sqrt{|s|}} \psi\left(\frac{t-u}{s}\right) u, s \in \mathbb{R}
\end{gathered}
$$

If $f$ is $L^{2}(\mathbb{R})$. function, its Continuous Wavelet Transform (TWC) is defined as:

$$
T W C(u, s)=\int_{-\infty}^{\infty} f(t) \psi_{s}^{u}(t) d t
$$

Since the $T W C$ is defined for continuous $L^{2}(\mathbb{R})$ functions, usually for the purpose of implementing it computationally, a discrete version has been built. One way to discretize the parameters of scale and frequency is through an exponential sampling on the variables $u$ and, to guarantee a better approximation with which the parameters $u$ and discrete values can be redefined, are defined then: $u=2^{-j} \in \mathbb{Z}$ y $s=k 2^{-j}$ with $j, k \in \mathbb{Z}$. Therefore, the relationship described in (10) is obtained.

$$
\psi_{j, k}(t)=2^{\frac{j}{2}} \psi\left(2^{j} t-k\right)
$$

With this selection of $u$ and $s$ the sampling in time is adjusted proportionally to the scale, on a larger scale, more distant points are taken, since global information is searched while at a smaller scale, details of the signal are searched, for this reason it is sampled in points less distant from each other.

Thus a function $\psi \in L^{2}(\mathbb{R})$ is Wavelet if the family of functions is an orthonormal basis fo $L^{2}(\mathbb{R})$.

In this case, the function $f$ can be expressed as a combination of the elements of the base, obtaining that:

$$
f(t)=\sum_{j, k} d_{j, k} 2^{\frac{j}{2}} \psi\left(2^{j} t-k\right) j, k \in \mathbb{Z}
$$

Where the set of coefficients $d_{j, k}$ defined in $j^{(11)}$ are the Discrete Wavelet Transform of $f$.

$$
d_{j, k}=\int_{-\infty}^{\infty} 2^{j / 2} f(t) \psi\left(2^{j} t-k\right) d t
$$

\subsection{MultiResolution Analysis (MRA)}

An MRA is increasing succession of closed subspaces $V_{j}, j \in \mathbb{Z}$ in $L^{2}(\mathbb{R})$ embedded, $\ldots V_{-1} \subset V_{0} \subset V_{1} \subset V_{2} \subset V_{3} \ldots$, that satisfy the next five conditions:

- $\mathrm{U}_{j} V_{j}$ Is dense in $L^{2}(\mathbb{R})$

- $\cap_{j} V_{j}=\{0\}$

- $f(t) \in V_{j} \Leftrightarrow f(2 t) \in V_{j+1}$

- $f(t) \in V_{0} \Leftrightarrow f(t-k) \in V_{j+1}$

- There is a function $\psi \in L^{2}(R)$ in which $\{\psi(t-k): k \in Z\}$ constitute orthonormal base for $\mathrm{V}_{0}$ space. Function $\psi$ is the scale function.

Being the set $W_{j}$ orthogonal compliment of each element $\mathrm{V}_{\mathrm{j}}$ in $\mathrm{V}_{\mathrm{j}+1}$ for each $j \in \mathbb{Z}$,is obtained, $V_{j} \cap W_{j}=\varnothing$, thus 
$V_{1}=V_{0} \oplus W_{1}, V_{2}=V_{1} \oplus W_{2}, \ldots, V_{j}=V_{j-1} \oplus W_{j}$, as explained in [3]. And replacing $V_{j}$ in $V_{j+1}$, for each $j \in \mathbb{Z}, V_{j}=V_{0} \oplus W_{1} \oplus W_{2} \oplus W_{2 \ldots} \oplus W_{j}$.

Now the set of linearly independent functions $\varphi_{j, \mathrm{k}, \mathrm{which}}$ generate to $V_{j}$ are named the scale functions, while those that generate $\mathrm{W}_{\mathrm{j}}$ are the same Wavelets. Thus, the functions $\psi$ show the "fine details" of the function, and the scales $\varphi$ "make an approximation" of $f$. This way the function $f$ can be approximated as a sum of these functions, as is shown in (13).

$$
\begin{gathered}
f(t) \sim \sum_{k} \sum_{j} c_{j, k} 2^{\frac{j}{2}} \varphi\left(2^{j} t-k\right)+d_{j, k} 2^{\frac{j}{2}} \psi\left(2^{j} t-k\right) \\
c_{j, k}=\int_{-\infty}^{\infty} f(t) \varphi_{j, k}(t) d t \quad d_{j, k}=\int_{-\infty}^{\infty} f(t) \psi_{j, k}(t) d t
\end{gathered}
$$

Where numbers $C_{j, k}$ y $D_{j, k}$ are the coefficients of the decomposition and the number of times the detail functions are extracted, that is the value of $J$ is the decomposition level.

\section{Applications of Wavelet transform to induction motor analysis}

Broad strokes it can be said that WT is used for several types of studies such as differentiating abnormal behavior of a signal, identifying discontinuities and points of drastic change, elimination of noise, compression of signal information and detection of self-similarities. In the case of electrical systems, applications from WT to IM have focused mainly on the diagnosis of faults, information analysis to feed the control systems and the identification of electromagnetic disturbances that affect the IM.

\subsection{Failure Diagnosis}

Failures that occur in an IM can be electrical or mechanical, and be originated by different reasons among which are the opening or shorting of one or more of a stator phase winding, incorrect connections in the stator windings, rotor field winding shorted, broken rotor bar or rotor end rings cracked, eccentricity, air gap irregularities, curved shaft, bearing and gearbox failures. The percentage of failures of the IM according to the information presented in [4] is distributed as follows Tread: $40 \%$, Stator winding: $38 \%$, Rotor: $10 \%$, Other various: $12 \%$.

There are techniques to detect and diagnose faults, those can be classified in the ones which do it with the motor in operation (on-line), and the other ones that are non-intrusive which do not require sensors. Generally, what is done to detect faults is a follow-up to the timefrequency evolutions of components related to faults during the transient of the starting current, these evolutions are identified, and also with a tool that can be TF or TTCF or WT, and the analysis of the results, the diagnosis of rotor or stator failure is concluded. There are several known methodologies among which are: The Motor Current Signature Analysis (MCSA) that is used to diagnose stator, short-circuit failure Motor Operated Valves (MOV's) for the detection of broken rotor bars in valves operated by motors in the Nuclear energy industry, Electrical Signature Analysis (ESA), which takes into account both voltage and current signatures. For its identification of signatures, the TF, TFST have been used, but recently the WT is being applied.

For the detection and extraction of machines faults classification patterns investigations [5-13] are found, which from identifying current signatures characterize what type of failure is occurring in the IM. The broken bars of the rotor are one of the most difficult faults to detect, especially when the motor is powered by an inverter [14]. In [15] a methodology is proposed for an IM powered by an inverter during the start followed by a regime in steady state, and the ability to identify a single broken rotor bar, an eccentricity, and the combination of both faults is verified. The works exposed in [16-25] use the WT for this diagnosis of faults only of the rotor; while to detect the stator faults the works of [26-29] which DWT is applied to the stator current signal to calculate the energy associated with the Stator failure in the bandwidth of frequency where the total effects of the stator faults are located. And for the faults in the in-between iron which are less frequent, results with experimental validation are shown in [30-31].

In [32] comparisons of stator and rotor electrical faults are made through an IM model that uses Park's Instantaneous Space Fasor during the stator current analysis and the Transformer Fast Fourier (TFF), to identify the spectrum and the spectral density band of the Wavelet coefficients. One of the most frequent problems are those that occur in the bearings as reported by "---[33-38] where are proposed techniques to make a diagnosis based on the analysis of the wavelet coefficients. The bearing damage detection technique presented in "[35], for example, uses the Wavelet Packet energy coefficient analysis method to detect the Interior Rail Fault severity level (IRF) and an exterior Rail Fault (ORF). 
In some cases the energy information associated with the faults is used as input to a neural network [39-44] which detects and locates it immediately. In other cases, in order to improve the results, the information obtained with WT has been combined with that extracted one using the Hilbert Transform [41], [45-46]. Wavelet with fuzzy logic has also been proposed to identify and quantify faults [47-48]. In [49] Wavelet with fuzzy logic has also been proposed to identify and quantify faults [50-51] as an input for Vector Support Machines (SVM) with which the conditions of the treads are classified [51].

Using MAR have been developed investigations as [5256] which are focus on the application of WT to study voltage and current signals. Allowing visualizing good resolution in time and a poor resolution in frequency for high frequencies and a good resolution in frequency and lowing in time for low frequencies.

\subsection{Control system}

With the Fault Tolerant Control, it is intended to detect incipient failures in sensors and/or actuators, and quickly adapt the system for its proper functioning. In the review article [57], a large number of investigations are presented which have implemented WT for fault-tolerant control systems. In this article it is concluded, from the analysis of the researches reviewed, that Wavelet provides an effective method for the diagnosis of faults in comparison with other methods of signal processing. The Wavelet can correctly distinguish faults and thermal effects that make the IM parameters vary such as resistance and inductance.

In [58] it is proposed a speed controller for a vector control system without speed sensor, for this they apply the WT to the torque signal that is estimated through an observer. In [59] it is used to decompose the electromagnetic torque signal and optimize the inverter control strategy. Since the WT provides good information on Current Transients, and has shown good results in the applications that have been implemented, there are several proposals to implement WT in Control systems [59-67].

\subsection{Electromagnetic disturbances}

In the case of electromagnetic disturbances it has been observed that wavelet coefficients alone can be used as an efficient variable for the detection and identification of disturbances [68-71].

In [72] two algorithms based on WT which have detection and classification mechanisms are developed, to diagnose and detect different disturbances which happen in three-phase IM. Due to with WT is possible to decompose voltage wave forms and analyze the change in signal energy of three-phase instant power during the voltage dips, good results have been obtained in $[73-75]$.

Research showed in [52] applies WT to torque and speed signal, to analyze voltage dips indirectly, studying the effect produced by the mechanical variable. It is affirmed that mechanical variables contain information about the sort of three-phase tension gap produced in the stator. The results of the decomposition with TW of the disturbed signals of the torque and speed of the motor shaft are also presented, when subjecting it to the different types of voltage dips according to the $\mathrm{ABC}$ classification.

Research that present criteria for deciding which Mother Wavelet and from which order it must be used in different problems that require frequency spectrum analysis are not found. Although some authors affirm that Mother Wavelet with Daubechies filters for energy quality analysis is quite trustworthy [54].

Although, there are no methods to select the right Wavelet for specific signal treatment, it is recognized the existence of the right Daubechies to apply in discreet signal analysis, Coiflet and Symmlet which being similar to Daubechies have symmetry. Biorthonormals is a family that presents lineal phase property what is really useful for image rebuilding, in this case it is necessary to use a Mother Wavelet to decompose and other to rebuild. In [76] $\mathrm{t}$ is proposed a method that selects the right Wavelet for transient electrical signals.

Some research which show the use of Wavelet but don't correspond with the groups previously shown are for example the one reported in [77], which is a proposal of a non-intrusive in-situ efficiency estimation method and tool for IM without any shaft or rotation sensor. There also show some works which are engaged in characterize electric systems waves [78-79]. In [80] a detailed comparison is made between the two main groups of transformations that are used in the transient analysis: discrete and continuous. 


\section{Conclusions}

WT has been applied in IM signals analysis with important results: the most frequent of those enforcements are the ones related with motor failure detection, control systems and electromagnetic perturbations identification which are shown in the power supply.

Furthermore, about failure detection, the results show that energy coefficients from Wavelet are not only sensitive to detect failures but also to detect the severity of the failure. In the cases in which WT data is mixed with other algorithms, strong results in accuracy and calculation time are generated.

On the research analyzed it is not specified if results obtained apply to high, medium or low power motors, and only in punctual cases it is mentioned the load and speed conditions of operation for which experimental tests were made.

There are not important advances to choose the most appropriate Wavelets for and specific sort of problem.

\section{References}

[1] C. M. Londoño-Parra, J. L. RamírezEchavarría, and L. C. Ramírez, "Energy efficiency standards of induction motors, ¿are you prepared Latin America?", Tecnológicas, no. $30, \quad 2013, \quad p p . \quad 123-7799$. https://doi.org/10.22430/22565337.91.

[2] A. A. Jaramillo-Matta and L. Guash Pesquer, "Estimación de parámetros y efectos de los huecos de tensión en la máquina de inducción trifásica”, thesis, Universitat Rovira i Virgili, Spain, 2011.

[3] L. M. Nuñez-Ramirez, R. Galvez-Perez and H. E. Galvez-Perez, "Análisis Multiresolución”, Pesquimat, vol. 13, no. 2, 2010, pp. 59-76.

[4] D. V. Ramana and S. Baskar, "Diverse fault detection techniques of three-phase induction motor - A review”, International Conference Emerging Technological Trends, 2016, pp. $1-8$.

https://doi.org/10.1109/ICETT.2016.78737 79.

[5] Y. Gritli, S. B. Lee, F. Filippetti and L. Zarri, "Advanced Diagnosis of Outer Cage Damage in Double-Squirrel-Cage Induction Motors Under Time-Varying Conditions Based on Wavelet Analysis", IEEE Transactions on
Industry Applications, vol. 50, no. 3, 2014, pp. $\begin{array}{llllllllll}1 & 7 & 9 & 1 & - & 1 & 8 & 0 & 0\end{array}$. https://doi.org/10.1109/TIA.2013.2285958.

[6] H. L. Schmitt, P. R. Scalassara, A. Goedtel and W. Endo, "Detecting Bearing Faults in LineConnected Induction Motors Using Information Theory Measures and Neural Networks", Journal of Control, Automation and Electrical Systems, vol. 26, no. 5, 2015, pp. 535-544. https://doi.org/10.1007/s40313015-0203-5.

[7] A. Sapena-Bañó, M. Pineda-Sanchez, R. PuchePanadero, J. Martinez-Roman and D. Mati , "Fault Diagnosis of Rotating Electrical Machines in Transient Regime Using a Single Stator Current's FFT", IEEE Transactions on Instrumentation and Measurement, vol. 64, no. 11, $2015, \quad \mathrm{p} \mathrm{p.} \quad 3137-3146$. https://doi.org/10.1109/TIM.2015.2444240.

[8] A. L. Vitor, P. R. Scalassara, W. Endo and A. Goedtel, "Induction motor fault diagnosis using wavelets and coordinate transformations", 12th IEEE International Conference on Industry Applications ( I N D U S C O N ), $\quad 20016$. https://doi.org/10.1109/INDUSCON.2016.7 $\underline{874502}$.

[9] G. Jagadan, L. Gopi, S. George and J. Jacob, "Modeling and detection of inter-turn fault in induction motors using wavelet entropy estimation," International Review of Electrical Engineering, vol. 7, no. 1, 2012, pp. 3342-3352.

[10] L. Eren, M. A kar and M. J. Devaney, "Motor current signature analysis via four-channel FIR filter banks”, Measurement, vol. 89, 2016, pp. 322-327.

https://doi.org/10.1016/j.measurement.2016 .04 .025 .

[11] W. Abitha Memala and V. Rajini, "Single phasing fault identification using wavelet analysis", International Journal of Engineering and Technology, vol. 6, no. 6, 2015, pp. 27122721 .

[12] F. Abid, S. Zgarni and A. Braham, "Distinct Bearing Faults Detection in Induction Motor by a Hybrid Optimized SWPT and aiNetDAG SVM", IEEE Transactions on Energy 
Conversion, vol. 33, no. 4, 2018, pp. 1-8. https://doi.org/10.1109/TEC.2018.2839083.

[13] W. Abitha Memala and V. Rajini, "Wavelet coefficients and statistical parameters in fault diagnosis", International Journal of Applied Engineering Research, vol. 10, no. 3, 2015, pp. 7837-7842.

[14] T. A. Garcia-Calva, D. Morinigo-Sotelo and R. Romero-Troncoso, "Non-Uniform Time Resampling for Diagnosing Broken Rotor Bars in Inverter-Fed Induction Motors", IEEE Transactions on Industrial Electronics, vol. 64, no. 3, 2017, pp. 2306-2315. https://doi.org/10.1109/TIE.2016.2619318.

[15] R. J. Romero-Troncoso, A. Garcia-Perez, D. Morinigo-Sotelo, O. Duque-Perez, R. A. Osornio-Rios and M. A. Ibarra-Manzano, "Rotor unbalance and broken rotor bar detection in inverter-fed induction motors at start-up and steady-state regimes by high-resolution spectral analysis", Electric Power Systems Research, vol. 133, 2016, pp. $142-148$.

https://doi.org/10.1016/j.epsr.2015.12.009.

[16] A. Naha, A. K. Samanta, A. Routray and A. K. Deb, "A method for detecting halfbroken rotor bar in lightly loaded induction motors using current”, IEEE Transactions on Instrumentation and Measurement, vol. 65, no. $7,2016, \mathrm{p} \mathrm{p} .161614-1625$. https://doi.org/10.1109/TIM.2016.2540941.

[17] R. Kechida, A. Menacer and H. Talhaoui, "Approach signal for rotor fault detection in induction motors", Journal of Failure Analysis and Prevention, vol. 13, no. 3, 2013, pp. 346-352. https://doi.org/10.1007/s11668-013-9681-6.

[18] C. Rodriguez-Donate, R. J. Romero-Troncoso, A. Garcia-Perez and D. A. Razo-Montes, "FPGA based embedded system for induction motor failure monitoring at the start-up transient vibrations with wavelets", International Symposium on Industrial Embedded Systems, 2008, pp. 208-214. https://doi.org/10.1109/SIES.2008.4577701.

[19] S. K. Ahamed, S. Karmakar, M. Mitra and S. Sengupta, "Novel diagnosis technique of mass unbalance in rotor of induction motor by the analysis of motor starting current at no load through wavelet transform", International Conference on Electrical \& Computer Engineering (ICECE), 2010, pp. 474-477. https://doi.org/10.1109/ICELCE.2010.5700 $\underline{732}$.

[20] S. R. Kapoor, A. Vashishtha and Y. S. Jethoo, "Performance analysis of wavelet based techniques for electrical faults signature extraction for squirrel cage induction motor", International Conference on Signal Propagation and Computer Technology ( I C S P C T ) , 2014 , p p . $71-76$. https://doi.org/10.1109/ICSPCT.2014.68849 $\underline{33 .}$

[21] H. Keskes and A. Braham, "Recursive Undecimated Wavelet Packet Transform and DAG SVM for Induction Motor Diagnosis", IEEE Transactions on Industrial Informatics, vol. 11 , no. 5, 2015, pp. $1059-1066$. https://doi.org/10.1109/TII.2015.2462315.

[22] F. J. Villalobos-Piña and R. Álvarez-Salas, "Algoritmo robusto para el diagnóstico de fallas eléctricas en el motor de inducción trifásico basado en herramientas espectrales y ondeletas", Revista Iberoamericana de Automática e Informática Industrial RIAI, vol. 12, no. 3, 2015, pp. 292-303.

https://doi.org/10.1016/j.riai.2015.04.003.

[23] R. Miceli, Y. Gritli, A. Di Tommaso, F. Filippetti and C. Rossi, "Vibration signature analysis for monitoring rotor broken bar in double squirrel cage induction motors based on wavelet analysis", The International Journal for Computation and Mathematics in Electrical and Electronic Engineering, vol. 33, no. 5, 2014, pp. $1625-1641$.

https://doi.org/10.1108/COMPEL-09-20130304.

[24] S. A. Taher, M. Malekpour and M. Farshadnia, "Diagnosis of broken rotor bars in induction motors based on harmonic analysis of fault components using modified adaptive notch filter and discrete wavelet transform", Simulation Modelling Practice and Theory, vol. 44, 2014, pp. 26-41. https://doi.org/10.1016/j.simpat.2014.02.006 
[25] H. Kim, S. B. Lee, S. Park, S. H. Kia and G. A. Capolino, "Reliable Detection of Rotor Faults under the Influence of Low-Frequency Load Torque Oscillations for Applications with Speed Reduction Couplings", IEEE Transactions on Industry Applications, vol. 52, no. 2,2016, p p. $1460-1468$. https://doi.org/10.1109/TIA.2015.2508423.

[26] K. N. Gyftakis, S. B. Lee, J. Kappatou and J. A. Antonino-Daviu, "Identification of the broken bar fault in induction motors with rotor air ducts through the torque spectrum", International Conference on Electrical Machines (ICEM), 2014, pp. 1614-1620. https://doi.org/10.1109/ICELMA CH.2014.6 $\underline{960398}$.

[27] K. M. Siddiqui, K. Sahay and V. K. Giri, "Early; diagnosis of stator inter-turn fault in inverter driven induction motor by wavelet transform", IEEE 1st International Conference on Power Electronics, Intelligent Control and Energy Systems (ICPEICES), 2016 , pp. 1-6. https://doi.org/10.1109/ICPEICES.2016.78 $\underline{53647}$.

[28] M. Zajac and M. Sulowicz, "The detection of coil shorting in induction motors by means of wavelet analysis", Technical Transactions, no. 2, 2016, pp. 135-150.

http://doi.org/10.4467/2353737X CT.16.253. $\underline{6052}$.

[29] T. Kato, K. Inoue and K. Yoshida, "Diagnosis of stator-winding-turn faults of induction motor by direct detection of negative sequence currents", Electrical Engineering in Japan, vol. 186, no. 3, 2013.

https://doi.org/10.1002/eej.22350.

[30] K. M. Siddiqui, K. Sahay and V. K. Giri, "Early, diagnosis of airgap eccentricity fault in the inverter driven induction motor drives by wavelet transform”, Journal of Electrical Engineering, vol. 16, no. 2, 2016.

[31] K. Yahia, A. J. M. Cardoso, A. Ghoggal and S. E. Zouzou, "Induction motors airgap-eccentricity detection through the discrete wavelet transform of the apparent power signal under non-stationary operating conditions", ISA Transactions, vol. 53, no. 2, 2014, pp. 603-311. https://doi.org/10.1016/j.isatra.2013.12.002.
F. J. Villalobos-Piña, R. Alvarez-Salas, E. CabalYepez and A. Garcia-Perez, "Induction motor model validation using fast fourier transform and wavelet tools", 9th IEEE International Symposium on Diagnostics for Electric Machines, Power Electronics and Drives (SDEMPED), 2013 , pp. 192-199. https://doi.org/10.1109/DEMPED.2013.664 $\underline{5716}$.

[33] P. Ewert and A. Doros awska, "Zastosowanie analizy falkowej do wykrywania uszkodze

o ysk tocznych", Przegl dElektrotechniczny, vol. 93, no. 1, 2017.

https://doi.org/10.15199/48.2017.01.72.

[34] K. C. Deekshit, M. Gopala and R. Srinivasa, "Bearing Fault Diagnosis in 3 phase Induction Machine Using Current Spectral Subtraction with Different Wavelet Transform Techniques", Journal Electrical Systems, vol. 13, no. 1, 2017, pp. 143-159.

[35] R. K. Patel and V. K. Giri, "Condition monitoring of induction motor bearing based on bearing damage index", Archives of Electrical Engineering, vol. 66, no. 1, 2017, pp. 105-119. https://doi.org/10.1515/aee-2017-0008.

[36] R. K. Pate and V. K. Giri, "Induction motor bearing fault diagnosis using cascaded EMD and DWT techniques", International Journal of Applied Engineering Research, vol. 10, no. 11, 2015, pp. 28317-28330.

[37] A. H. Boudinar, N. Benouzza, A. Bendiabdellah and M. E. Khodja, "Induction motor bearing fault analysis using a root-MUSIC method", IEEE Transactions on Industry Applications, vol. 52, no. 5, 2016 , pp. 3851-3860. https://doi.org/10.1109/TIA.2016.2581143.

[38] R. Kianinezhad, P. Mirjani and S. G. Seifossadat, "Motor ballbearing outer race fault detection using wavelet packet decomposition, an experimental and simulation study", International Review of Electrical Engineering, vol. 7, no. 6, 2012, pp. 6116-6122.

[39] B. Bessam, A. Menacer, M. Boumehraz and H. Cherif, "A Novel Method for Induction Motors Stator Inter- Turn Short Circuit Fault Diagnosis based on Wavelet Energy and Neural Network", IEEE 10th International Symposium on Diagnostics for Electrical 
Machines, Power Electronics and Drives (SDEMPED), 2015 , p p. 143-149. https://doi.org/10.1109/DEMPED.2015.730 $\underline{3682}$.

[40] C. Wu, T. Chen, R. Jiang, L. Ning and Z. Jiang, "ANN based multi-classification using various signal processing techniques for bearing fault diagnosis", International Journal. Control Automation, vol. 8, no. 7, 2015.

[41] W. He, Y. Zi, B. Chen, F. Wu and Z. He, "Automatic fault feature extraction of mechanical anomaly on induction motor bearing using ensemble super-wavelet transform”, Mechanical Systems and Signal Processing, vol. 55, 2015 , pp. 457-480. https://doi.org/10.1016/j.ymssp.2014.09.007

[42] V. R. Jadhav and A. S. Patil, "Classification of voltage sags at Induction Motor by Artificial Neural Network", International Conference on Energy Systems and Applications, 2015, pp. $173-177$.

https://doi.org/10.1109/ICESA.2015.7503334.

[43] N. R. Devi, D. V. S. S. Siva Sarma and P. V. Ramana Rao, "Diagnosis and classification of stator winding insulation faults on a threephase induction motor using wavelet and MNN", IEEE Transactions on Dielectrics and Electrical Insulation, vol. 23, no. 5, 2016, pp. $2543-2555$. https://doi.org/10.1109/TDEI.2016.773681 $\underline{1 .}$

[44] D. A. Asfani, Syafaruddin, M. H. Purnomo, and T. Hlyama, "Neural network based real time detection of temporary short circuit fault on induction motor winding through wavelet transformation", International journal of innovative computing, information \& control: IJICIC, vol. 10, no. 6, 2014.

[45] P. Konar, J. Sil and P. Chattopadhyay, "Knowledge extraction using data mining for multi-class fault diagnosis of induction motor", Neurocomputing, vol. 166, 2015, pp. 14-25. https://doi.org/10.1016/j.neucom.2015.04.04 $\underline{0}$.

[46] P. Konar and P. Chattopadhyay, "Multi-class fault diagnosis of induction motor using Hilbert and Wavelet Transform", Applied Soft
Computing, vol. 30, 2015 , pp. 341-352. https://doi.org/10.1016/j.asoc.2014.11.062.

[47] E. Cabal-Yepez, R. J. Romero-Troncoso, A. Garcia-Perez and R. A. Osornio-Rios, "Singleparameter fault identification through information entropy analysis at the startuptransient current in induction motors", Electric Power Systems Research, vol. 89, 2012, pp. 64-69. https://doi.org/10.1016/j.epsr.2012.02.016.

[48] L. Souad, B. Azzedine, C. B. Eddine, B. Boualem, M. Samir and M. Youcef, "Induction machine rotor and stator faults detection by applying the DTW and N-F network", IEEE International Conference on Industrial Technology (ICIT), 2018 , pp. 431-436. https://doi.org/10.1109/ICIT.2018.8352216.

[49] W. Kai, B. Ming, C. Lin, Y. Ting and S. Huayu, "The method of fault detection and diagnosis for induction motors based on wavelets and independent component analysis", International Journal of Digital Content Technology and its Applications, vol. 5, no. 9, 2011, pp. 405-410. https://doi.org/10.4156/jdcta.vol5.issue9.45.

[50] S. Jaya and R. Vinodha, "Fault diagnose of induction motor using novel least square fuzzy total margin support vector machine", IIOAB Journal, vol. 7, no. 11, 2016.

[51] Q. Liu, F. Chen and Z. Zhou, "Fault Diagnosis of Rolling Bearing Based on Wavelet Package Transform and Ensemble Empirical Mode Decomposition", Advances in Mechanical Engine ering, vol. 5, 2013. https://doi.org/10.1155\%2F2013\%2F 792584

[52] M. G. Macri and M. Benedetti, "Análisis multirresolución del motor trifásico de inducción sometido a huecos de tensión", Ingeniare. Revista chilena de ingeniería, vol. 20, n o. 1,2012, p p. $66-78$. http://dx.doi.org/10.4067/S071833052012000100007.

[53] E. H. Bayoumi, "Multi-resolution analysis wavelet PI stator resistance estimator for direct torque induction motor drive", WSEAS Transactions on Circuits and Systems, vol. 12, no. 7, 2013, pp. 21 1-220. 
[54] R. A. Keswani, H. M. Suryawanshi and M. S. Ballal, "Multi-resolution analysis for converter switch faults identification", IET Power Electrononics, vol. 8, no. 5, 2015. https://doi.org/10.1049/iet-pel.2014.0450.

[55] H. B. A. Sethom and M. A. Ghedamsi, "Multiresolution Analysis based effective diagnosis of induction motors", American Journal of Applied Sciences, vol. 9, no. 5, 2012, p p. $\quad 624-632$. https://doi.org/10.3844/ajassp.2012.624.632.

[56] N. Khandelwal, P. Pareek and S. R. Kapoor, "Start-up Transient Current Analysis for Squirrel Cage Induction Motor", IEEE 1st International Conference on Power Electronics, Intelligent Control and Energy S y s t e m s ( I C P E I C E S ), 2016. https://doi.org/10.1109/ICPEICES.2016.78 $\underline{53261 .}$.

[57] K. Salloum Gaeid and H. Wooi Ping, "Wavelet fault diagnosis and tolerant of induction motor: A review", International journal of physicalsciences, vol. 6, no. 3, 2011, pp. 358-376.

[58] H. Watanabe and N. Kasa, "A torque ripples compensating technique based on disturbance observer with wavelet transform for sensorless induction motor drives", IECON '98. Proceedings of the 24th Annual Conference of the IEEE, 1998 , p p. $580-585$. https://doi.org/10.1109/IECON.1998.72415 z.

[59] K. Shanlin and K. Yuzhe, "Optimization Design of Wavelet Network for Estimation of Flux and Torque in Induction Motor Control System", 8th International Conference on Electronic Measurement and Instruments, $2007, \quad$ p p . $3-433$. https://doi.org/10.1109/ICEMI.2007.43509 47.

[60] C. B. Eddine, B. Azzeddine and B. Mokhtar, "Detection of a two-level inverter open-circuit fault using the discrete wavelet transforms technique", IEEE International Conference on Industrial Technology (ICIT), 2018, pp. $370-376$.

https://doi.org/10.1109/ICIT.2018.8352206.

[61] S. Jeevanand and A. T. Mathew, "Condition Monitoring of Induction Motors Using
Wavelet Based Analysis of Vibration Signals", Second International Conference on Future Generation Communication and Networking S y m posia, 2008 , p p. $75-80$. https://doi.org/10.1109/FGCNS.2008.22.

[62] H. Talhaoui, A. Menacer, A. Kessal and R. Kechida, "Fast Fourier and discrete wavelet transforms applied to sensorless vector control induction motor for rotor bar faults diagnosis", ISA Transactions, vol. 53, no. 5, 2014, pp. $\begin{array}{lllllllll}1 & 6 & 3 & 9 & - & 1 & 6 & 4 & 9\end{array}$. https://doi.org/10.1016/j.isatra.2014.06.003.

[63] O. A. S. Youssef, "Fault classification based on wavelet transforms", 2001 IEEE/PES Transmission and Distribution Conference and Exposition. Developing New Perspectives, 2001 , pp. $531-536$. https://doi.org/10.1109/TDC.2001.971290.

[64] E. Cabal-Yepez, A. G. Garcia-Ramirez, R. J. Romero-Troncoso, A. Garcia-Perez, and R. A. Osornio-Rios, "Reconfigurable monitoring system for time-frequency analysis on industrial equipment through STFT and DWT", IEEE Transactions on Industrial Informatics, vol. 9, no. 2, 2013, pp. $760-771$. https://doi.org/10.1109/TII.2012.2221131.

[65] S. Padmanaban et al., "Wavelet-fuzzy speed indirect field oriented controller for threephase AC motor drive - Investigation and implementation", Engineering Science and Technology, an International Journal, vol. 19, no. 3,2016 , p p. $1099-1107$. https://doi.org/10.1016/j.jestch.2015.11.007.

[66] P. Sanjeevikumar et al., "Wavelet Transform with Fuzzy Tuning Based Indirect Field Oriented Speed Control of Three- Phase Induction Motor Drive", International Conference on Electrical Drives and Power Electronics (EDPE), 2015 , pp. 21-23. https://doi.org/10.1109/EDPE.2015.732527 $\underline{9}$.

[67] R. Roshanfekr and A. Jalilian, "Wavelet-based index to discriminate between minor inter-turn short-circuit and resistive asymmetrical faults in stator windings of doubly fed induction generators: a simulation study", IET 
Generation, Transmission E Distribution, vol. 10, no. 2, 2016, pp. 374-381. https://doi.org/10.1049/iet-gtd.2015.0545.

[68] S. Sridhar, K. U. Rao and S. Jade, "Detection and classification of PQ disturbances in the supply to induction motor using wavelet transform and feedforward neural network", IEEE International Conference on Electrical, Computer and Communication Technologies ( I C E C C T ), 2015, p p . $1-5$. https://doi.org/10.1109/ICECCT.2015.7225 930.

[69] M. A. Khan and M. A. Rahman, "Discrete Wavelet Transform Based Detection of Disturbances in Induction Motors", International Conference on Electrical and Computer Engineering, 2006, pp. 462-465. https://doi.org/10.1109/ICECE.2006.35566 $\underline{9}$.

[70] S. Santoso, E. J. Powers, W. M. Grady and P. Hofmann, "Power quality assessment via wavelet transform analysis", IEEE Transactions on Power Delivery, vol. 11, no. 2, 1996, pp. 924-930. https://doi.org/10.1109/61.489353.

[71] A. M. Gaouda, M. M. A. Salama, M. R. Sultan and A. Y. Chikhani, "Power quality detection and classification using waveletmultiresolution signal decomposition," IEEE Transactions on Power Delivery, vol. 14, no. 4, 1999 , p p. $1469-1476$. https://doi.org/10.1109/61.796242.

[72] H. Ismail, N. Hamzah, S. Shahbudin and Z. Zakaria, "Comparative analysis of input parameters using wavelet transform for voltage sag disturbance classification", IEEE International Conference on Software Engineering and Service Sciences, 2010, pp. $5 \quad-\quad 8$. https://doi.org/10.1109/ICSESS.2010.55523 $\underline{50}$.

[73] X. Zhang and Y. Xu, "Analysis of Voltage Sag Source Location Based on WaveletMultiresolution Method", Asia-Pacific Power and Energy Engineering Conference, 2010, pp. $1-4$

https://doi.org/10.1109/APPEEC.2010.5448 152 .

[74] S. A. Saleh, M. A. Khan and M. A. Rahman, "Application of a wavelet-based MRA for diagnosing disturbances in a three-phase induction motor", 5th IEEE International Symposium on Diagnostics for Electric
Machines, Power Electronics and Drives, 2005, p p. $1-6$ https://doi.org/10.1109/DEMPED.2005.466 $\underline{2523}$.

[75] D. Chanda, N. K. Kishore and A. K. Sinha, "Application of wavelet multiresolution analysis for identification and classification of faults on transmission lines", Electric Power Systems Research, vol. 73, no. 3, 2005, pp. 323-333

https://doi.org/10.1016/j.epsr.2004.07.006.

[76] E. Gómez, G. Aponte and D. Silva, "Selección de una wavelet madre para el análisis frecuencial de señales eléctricas transitorias", Ingeniare, vol. 21, no. 2, 2013 , pp. 262-270. https://doi.org/10.4067/So71833052013000200009.

[77] H.-S. Chuang, Y.-C. Chuang and C.-H. Yang, "Non-intrusive efficiency estimation of induction motor based on on-site measurements", ICIC Express Letter Part B: Applications, vol. 6, no. 12, 2015, pp. 31733181.

[78] A. Hovanessian and M.-A. Norouzi, "Islanding detection using wavelet transform and rate of change of frequency relay method in presence of different distributed generation technologies", IEEJ Transactions on Electrical and Electronic Engineering, vol. 11, 2016. https://doi.org/10.1002/tee.22238.

[79] J. F. Hernandez-Perez, D. Vela-Arvizo, J. M. Rodriguez-Lelis, J. L. Orta-Acuna, D. TolosaMata and M. Vargas-Trevino, "A Morlet Wavelet Signal Analysis with a Daubechies Filter for Power Quality Disturbances", Electronics, Robotics and Automotive Mechanics Conference (CERMA 2007), 2007, p p. $675-680$.

https://doi.org/10.1109/CERMA.2007.4367 $\underline{765}$.

[80] J. Pons-Llinares, J. A. Antonino-Daviu, M. Riera-Guasp, S. B. Lee, T.-J. Kang and C. Yang, "Advanced induction motor rotor fault diagnosis via continuous and discrete timefrequency tools", IEEE Transactions on Industrial Electronics, vol. 62, no. 3, 2015, pp. $1791-1802$ https://doi.org/10.1109/TIE.2014.2355816. 